\title{
Der gesellschaftsrechtliche Minderheitenschutz bei grenzüberschreitender Verschmelzung von Kapitalgesellschaften
}

Eine Untersuchung zum Spruchverfahrensrecht unter besonderer Berücksichtigung internationalzivilverfahrensrechtlicher Aspekte

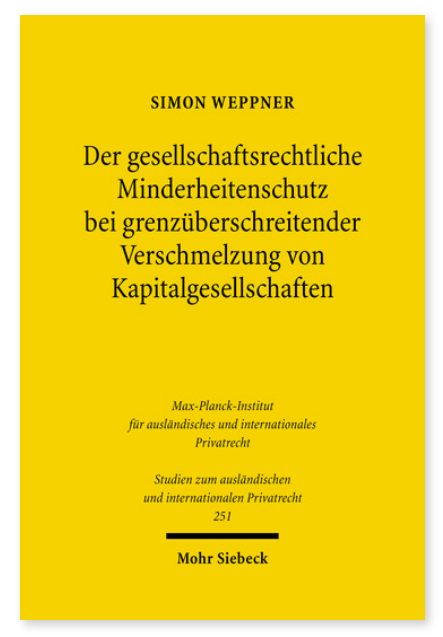

2010. XXIV, 233 Seiten. StudIPR 251

ISBN 978-3-16-151436-4

DOI 10.1628/978-3-16-151436-4 eBook PDF 69,00€

ISBN 978-3-16-150658-1

fadengeheftete Broschur 69,00€
Der Schutz von Minderheitsgesellschaftern bei der Durchführung von gesellschaftsrechtlichen Strukturmaßnahmen gehört zum Kernbestand des gesellschaftsrechtlichen Minderheitenschutzes. Aus diesem Grund können Gesellschafter auch bei einer grenzüberschreitenden Verschmelzung nach Maßgabe der SE-VO bzw. Verschmelzungsrichtlinie im Grundsatz die gerichtliche Überprüfung des Umtauschverhältnisses ihrer Anteile und die Höhe der ihnen angebotenen Barabfindung beantragen. Hierfür stellt das deutsche Zivilprozessrecht eine eigens auf die Bedürfnisse dieses Verfahrens zugeschnittene Verfahrensordnung zur Verfügung, das SpruchG. Welche Konflikte sich aus dem Zusammenspiel des Spruchverfahrens mit dem internationalen Zivilverfahrensrecht ergeben und wie diese zu lösen sind, untersucht Simon Weppner in seiner Studie zum internationalen Zivil- bzw. Spruchverfahrensrecht.

Simon Weppner Geboren 1976; Studium der Rechtswissenschaft in Heidelberg und Mannheim, 2002 Master of Comparative Law (Adelaide), seit 2007 Rechtsanwalt, 2010 Promotion.
Jetzt bestellen:
https://mohrsiebeck.com/buch/der-gesellschaftsrechtliche-minderheitenschutz-bei-grenzueberschreitender-verschmelzung-
von-kapitalgesellschaften-9783161514364?no_cache=1
order@mohrsiebeck.com
Telefon: +49 (0)7071-923-17
Telefax: +49 (0)7071-51104 